\title{
Prevalence and risk factors of depression and diabetes- related emotional distress in patients with type 2 diabetes: A cross-sectional study
}

\author{
Anita T. Faber-Wildeboer ${ }^{1}$, Harmieke van Os-Medendorp ${ }^{2}$, Adriaan Kooy ${ }^{3}$, Berna G.M. Sol ${ }^{4}$ \\ 1. Bethesda Diabetes Research Center, Hoogeveen, The Netherlands. 2. Dept of dermatology, University Medical Center \\ Utrecht, The Netherlands. 3. Dept of internal medicine, Bethesda General Hospital, Hoogeveen, The Netherlands. 4. Dept. \\ of Endocrinology, University Medical Center Utrecht, The Netherlands
}

Correspondence: Anita T. Faber-Wildeboer. Address: Dr. G. H. Amshoffweg 1, 7909 RA Hoogeveen, The Netherlands. Telephone: 0031-646-072-083. Email: faber.a@bethesda.nl.

Received: August 24, 2012

Accepted: September 27, 2012

Online Published: December 27, 2012

DOI : $10.5430 /$ jnep.v3n6p61

URL: http://dx.doi.org/10.5430/jnep.v3n6p61

\begin{abstract}
Objective: The purpose of this study was to investigate the prevalence of depression and diabetes-related distress, and their associated risk factors, in patients with type 2 diabetes attending a diabetes center of a Dutch general hospital.

Methods: A cross-sectional study of 147 adults with insulin-treated type 2 diabetes during the period January-May 2011. Data on depression and diabetes-related distress rates were collected using the WHO-5 and PAID self-reported questionnaires. Hierarchical multiple regression analyses were performed.

Results: The prevalence of poor well-being (WHO-5 score $<28-50>$ ) was $9.6 \%$ and that of depression (WHO-5 score $\leq$ 28) was $12.9 \%$. Significant risk factors for depression were diabetes-related distress, stress due to life events in the past 12 months, female gender, and educational level. The prevalence of diabetes-related distress (PAID score $\geq 33$ ) was $8.8 \%$, and significant risk factors were well-being and $\mathrm{HbA1C}$ levels.

Conclusions: While the prevalence of depression in the overall Dutch population is approximately $6.2 \%$, the prevalence of depression or diabetes-related distress in patients with insulin-treated type 2 diabetes attending a Dutch diabetescenter, is approximately $20 \%$. Findings support the routine screening of patients with diabetes for depression and diabetes-related distress. In addition to well-known demographic, clinical, and psychosocial factors, stress due to life events in the past 12 months was identified as a risk factor of depression. The diabetes nurse specialists (DNSs) play a key role in counseling the process of behavioral change and supporting self-management in their patients. Paying attention to significant risk factors may be valuable for DNSs to detect and monitor psychological distress; which may improve treatment outcomes.
\end{abstract}

\section{Key words}

Type 2 diabetes, Depression, Prevalence, Well-being, Diabetes-related distress, Risk factors

\section{I ntroduction}

The prevalence of diabetes is increasing worldwide and was estimated to be 6.4\% among adults (age 20-79 years) in 2010 and is estimated to be $7.7 \%$ by $2030^{[1]}$. Diabetes is often complicated by cardiovascular disease, neuropathy, nephropathy, 
and/or retinopathy. The primary aim of treatment, which usually consists of lifestyle changes and polypharmacy with oral antihyperglycemic agents, insulin, and antihypertensive and cholesterol-lowering drugs, is to achieve normal blood glucose levels with a view to preventing complications and maintaining a good quality of life ${ }^{[2]}$. Self-management is an essential element of diabetes care and refers to the individual's ability to manage symptoms, treatment, physical and psychological consequences, and lifestyle changes inherent to this chronic condition ${ }^{[3]}$. Diabetes management requires long-term adherence to diet, physical activity, medication, and frequent monitoring of blood glucose levels, and patients have to learn to integrate self-management into their daily lives and to cope with complications. The diabetes nurse specialists (DNSs) play a key role in coordinating the process of behavioral change and supporting self-management ${ }^{[4,5]}$ by discussing influential factors, such as adverse life events and well-being, with the patient ${ }^{[6]}$. The continued need for self-management makes patients with diabetes vulnerable to psychological distress, such as depression and emotional distress ${ }^{[7]}$. Chronic depression can seriously hamper an individual's ability to take care of everyday responsibilities. Depression affects about $6.2 \%$ of the general Dutch population, but especially affects people aged 25-45 years and women ${ }^{[8]}$. The prevalence of depression in patients with type 2 diabetes is significantly higher than that in the general population ( $17.6 \%$ vs. $9.8 \%$, respectively; $p<0.0001)^{[9]}$. People with diabetes can also experience subclinical emotional distress, such as feelings of guilt, frustration, being overwhelmed, anger, or fear ${ }^{[7]}$. Studies have shown that depression and diabetes-related distress can disrupt self-management ${ }^{[10]}$ and worsen glycemic control ${ }^{[11,12]}$, thereby increasing the risk of complications ${ }^{[13-16]}$, mortality ${ }^{[16]}$, and loss of quality of life ${ }^{[17]}$. Risk factors for depression are female gender ${ }^{[9,18]}$, age $<64$ years ${ }^{[19,20]}$, low education ${ }^{[19]}$, presence of complications ${ }^{[21]}$, major life events ${ }^{[22]}$, functional limitations ${ }^{[21]}$, poor glycemic control ${ }^{[7,11]}$, and insulin treatment ${ }^{[23]}$. Efficient psychological care such as cognitive behavioral therapy or medication is available ${ }^{[7]}$. Unfortunately the detection rate of depression in patients with diabetes, which is an important condition for treatment, is still low ${ }^{[24]}$. Given the importance of a timely diagnosis and treatment of psychosocial distress, and screening for depression and diabetes-related distress in patients with diabetes should be integrated in structural

diabetes care ${ }^{[2,4,25-27]}$. To support the need for such screening, the aim of this study was to estimate the prevalence of depression and diabetes-related distress and to investigate relevant risk factors in patients attending a diabetes center.

\section{Methods}

\subsection{Patients}

In this cross-sectional study, patients with type 2 diabetes attending the diabetes center of a Dutch general hospital (January - May 2011) were eligible for participation. Eligibility criteria were age $>18$ years, diagnosis type 2 diabetes with or without complications, and taking insulin for $>1$ year. Exclusion criteria were treatment with only oral diabetes medication, an impaired ability to complete questionnaires due to psychiatric, visual, or other disorders. All eligible patients were told about the study and were invited to participate by the DNSs after their scheduled visit. Patients who were willing to participate received written information about the study, a letter inviting them to participate, an informed consent form, and questionnaires in an envelope handed out by the DNSs. The questionnaires could be filled in at home and sent anonymously to the principal investigator (A.F). The study was carried out accordingly to the principles of the Declaration of Helsinki ${ }^{[28]}$ and was approved by the hospital's Internal Review Board Committee.

\subsection{Measurements}

Demographic and clinical characteristics, including age (in years), gender, marital status, educational level (high education being defined as secondary school or university), year of diabetes onset, history of treatment by psychologist or psychiatrist (yes/no), and current stress due to a life event in the last 12 months (yes/no), were assessed by self-report. Life events were described as the presence of illness, death in the social network, loss of business, divorce, or moving house. Information about complications, functional limitations, and $\mathrm{HbA1C}$ levels was obtained from the medical records. Macro- and micro-vascular complications were defined as cardiovascular disease (myocardial infarction, stroke, or peripheral arteriosclerosis), retinopathy (background, pre-proliferative or proliferative), neuropathy (absence or reduced 
vibratory sensation and/or diabetic foot ulcers), and nephropathy (positive micro- or macro-albuminuria or decreased renal function with a glomerular filtration rate of $<60 \mathrm{~mL} / \mathrm{min}$ per $1.73 \mathrm{~m}^{2}$ ). Complications such as dyspnea of effort, angina pectoris, pain, and invalidity were noted.

Depression was measured using the short version of the World Health Organization (WHO) Well-Being Scale ${ }^{[29]}$. This scale (WHO-5) was designed to measure psychological well-being and has been validated in different populations, including patients with diabetes ${ }^{[30-32]}$. The WHO-5 questionnaire is recommended by the WHO as a first step in a two-stage screening process for depression and should be followed by a structured clinical interview according to the Diagnostic and Statistical Manual of Mental Disorders to confirm the diagnosis ${ }^{[33]}$. The positively formulated items of the WHO-5 questionnaire are related to mood (good spirits, relaxation), vitality (being active and waking up fresh and rested), and general interests (being interested in things) in the previous 2 weeks and are scored on a 6-point Likert scale, ranging from 0 (not present) to 5 (constantly present). Total scores were transformed to a $0-100$ scale to compare the results ${ }^{[18]}$. A score below 50 suggests poor emotional well-being and a score below 28 is indicative of depression ${ }^{[30-32]}$, with a sensitivity of $100 \%$ and a specificity of $74.1 \%{ }^{[32]}$. In the current study population, the WHO-5 scale had an internal consistency (Cronbach alpha coefficient) of .90 , which is sufficient ${ }^{[34]}$.

Diabetes-related distress was measured with the validated Problem Areas in Diabetes-scale (PAID), a screening instrument for depression and diabetes-related distress ${ }^{[27-35]}$. This scale measures four problem areas in diabetes: negative emotions (12 items), concerns regarding treatment ( 3 items), food-related problems (3 items), and social support-related problems ( 2 items), scored on a 5-point Likert scale (0-4), ranging from 'no problem at all' to 'a very serious problem'. Total scores were transformed to a $0-100$ scale. Higher scores are indicative of greater emotional distress. A cut-off score $\geq 33$ is appropriate for detecting clinical and subclinical depression with a sensitivity of $79 \%$ and a specificity of $76 \%{ }^{[27]}$. In the current study, the PAID scale had a Cronbach alpha coefficient of .93, which is sufficient ${ }^{[34]}$.

\subsection{Statistical analyses}

Statistical analyses were performed using SPSS version 19.0 UK (SPSS Inc., Chicago, IL). Descriptive statistics were used to calculate percentages, means, and standard deviations of demographic and clinical variables. Differences between men and women were measured using $\chi^{2}$ test for categorical variables and Student's $t$-test for continuous variables. Hierarchical multiple regression was used to investigate the influence of demographic, clinical, and psychosocial factors on depression and diabetes-related distress. As recommended by Pollit et al, a sample size of at least 115 participants was needed for the multiple regression analyses ${ }^{[36]}$. Independent variables were entered in three blocks. The first block contained demographic variables (age, education, marital state, and gender), the second block contained psychosocial variables (WHO-5 or PAID scores and stress due to life events), and the third block contained clinical variables (HbA1C, diabetes complications, and diabetes duration). A $p$-value of $<0.05$ (two tailed) was considered to be statistically significant in all analyses. Preliminary analyses were performed to ensure no violation of the assumptions of normality, linearity, and homogeneity of variance.

\section{Results and discussion}

\subsection{Baseline characteristics}

Of the 276 patients recruited, 46 patients did not give their informed consent because of feeling stressed at that moment, difficulties, lack of interest, lack of time, lack of understanding, and forgetfulness on the part of the DNSs. Of the 230 patients who provided their consent, 147 participants returned completed questionnaires (response rate $64 \%$ ). The reasons for non-response are not known. Baseline demographic and clinical characteristics are reported in table 1. All patients were of Caucasian origin, and there were no differences in demographic and clinical variables between men and women. 
Table 1. Baseline characteristics of the study population

\begin{tabular}{|c|c|c|}
\hline & Item & Percentage \\
\hline \multicolumn{3}{|l|}{ Demographics values $(n=147)$} \\
\hline & male $(\mathrm{n}, \%)$ & $87(59.2)$ \\
\hline & age in years $($ mean $\pm \mathrm{SD})$ & $65.9 \pm 9.7$ \\
\hline & married or partner $(\mathrm{n}, \%)$ & $112(76.2)$ \\
\hline \multicolumn{3}{|l|}{ Education Level $(n=146)$} \\
\hline & low education (n, \%) & $80(54.8)$ \\
\hline & medium or high education $(\mathrm{n}, \%)$ & $66(45.2)$ \\
\hline \multicolumn{3}{|l|}{ Emotional well-being $(n=145)$} \\
\hline & life event experienced in last 12 months (n, \%) & $54(37.2)$ \\
\hline & psychologist / psychiatrist ever (n, \%) & $15(10.3)$ \\
\hline \multicolumn{3}{|l|}{ Clinical values $(n=147)$} \\
\hline & $\mathrm{HbA} 1 \mathrm{C}$ in $\mathrm{mmol} / \mathrm{mol}($ mean $\pm \mathrm{SD})$ & $54.6 \pm 11.2$ \\
\hline & $\mathrm{HbA} 1 \mathrm{C}$ in $\mathrm{mg} / \mathrm{dL}($ mean $\pm \mathrm{SD})$ & $158.4 \pm 44.4$ \\
\hline \multicolumn{3}{|l|}{ Complications $(n=106)$} \\
\hline & cardiovascular disease (n, \%) & $54(36.7)$ \\
\hline & retinopathy $(\mathrm{n}, \%)$ & $16(10.9)$ \\
\hline & nephropathy (n, \%) & $27(18.4)$ \\
\hline & neuropathy (n, \%) & $9(6.1)$ \\
\hline \multicolumn{3}{|l|}{ Functional limitations $(n=106)$} \\
\hline & $\begin{array}{l}\text { dyspnea of effort, pain due to intermittent claudication or } \\
\text { neuropathy, disability due to amputation or } \\
\text { cerebrovascular accident (n, \%) }\end{array}$ & $30(28.3)^{*}$ \\
\hline \multicolumn{3}{|l|}{ Duration of diabetes $(n=147)$} \\
\hline & diabetes duration in years (mean $\pm \mathrm{SD}$ ) & $15.6 \pm 9.5$ \\
\hline
\end{tabular}

Note. HbA1C (glycated hemoglobin) levels are measured in the last 4 months. SD, Standard Deviation. Cardiovascular disease, myocardial infarction, stroke, or peripheral arteriosclerosis. Retinopathy, background, pre- or proliferative. Neuropathy, absence or reduced vibratory sensation and/or diabetic foot ulcers. Nephropathy, albuminuria or decreased renal function with a glomerular filtration rate of $<60 \mathrm{~mL} / \mathrm{min}$ per $1.73 \mathrm{~m} 2$ ). Low education is defined as no education or primary school; medium education is defined as vocational education; and high education is defined as secondary school and university. * missing reports in 28 cases

\subsection{Prevalence of depression}

In table 2, mean WHO-5 and PAID scores are presented for the total sample and by gender. Fourteen patients $(9.5 \%)$ experienced poor emotional well-being (WHO-5 $<28-50>$ ) and 19 (12.9\%) depression (WHO-5 score $\leq 28$ ). Mean scores were significantly different in men and women ( $\mathrm{MD}=12.77,95 \% \mathrm{CI}: 4.44$ to 21.10). Patients who reported being stressed because of a recent life event had significantly lower WHO-5 scores than did those without such stress $(53.7 \pm 25.6$ versus $71.8 \pm 21.7$, respectively; $t(143)=4.56, p<0.0001)$. Four patients $(2.7 \%)$ with poor well-being $($ WHO- $5 \leq 50)$ and four patients $(2.7 \%)$ with depression (WHO-5 $\leq 28)$ also had high levels of diabetes-related distress (PAID $\geq 33$ ).

Table 2. Prevalence of depression (WHO-5) and diabetes-related emotional distress (PAID) in men and women

\begin{tabular}{llllll}
\hline & & Total $\mathbf{n = 1 4 7}$ & men $\mathbf{n = 8 7}$ & women $\mathbf{n = 6 0}$ & Mean Difference (95 \% confidence interval) \\
\hline WHO & mean \pm SD & $65.2 \pm 24.5$ & $70.4 \pm 20.7$ & $57.7 \pm 27.6$ & 12.77 (4.44 to 21.1) \\
total $<28-50>$ & $\mathrm{n}(\%)$ & $14(9.5)$ & $9(10.3)$ & $5(8.3)$ & \\
total $\leq 28$ & $\mathrm{n}(\%)$ & $19(12.9)$ & $5(5.7)$ & $14(23.3)$ & \\
PAID & mean \pm SD & $13.3 \pm 13.8$ & $12.0 \pm 12.8$ & $15.2 \pm 14.9$ & -3.17 (-7.72 to 1.38) \\
total $\geq 33$ & $\mathrm{n}(\%)$ & $13(8.8)$ & $7(8.0)$ & $6(10.0)$ & \\
\hline
\end{tabular}


Table 3. Demographic, psychosocial, and clinical predictors of depression (WHO-5) in type 2 diabetes patients

\begin{tabular}{|c|c|c|c|c|}
\hline Final model & Standardized Beta & $t$ & $p$ & $\mathbf{R}$ square \\
\hline \multicolumn{5}{|c|}{ 1. Demographic variables } \\
\hline female & -0.157 & -2.006 & 0.047 & \multirow{4}{*}{0.135} \\
\hline low education & 0.146 & 1.944 & 0.054 & \\
\hline relation & 0.066 & 0.898 & 0.371 & \\
\hline age & -0.078 & -0.966 & 0.336 & \\
\hline \multicolumn{5}{|c|}{ 2. Psychosocial variables } \\
\hline diabetes distress & -0.394 & -5.306 & 0.000 & \multirow{2}{*}{0.343} \\
\hline life events & -0.282 & -3.892 & 0.000 & \\
\hline \multicolumn{5}{|l|}{ 3. Clinical variables } \\
\hline duration of diabetes & 0.066 & 0.883 & 0.379 & \multirow{3}{*}{0.354} \\
\hline $\mathrm{HbA1C}$ & 0.063 & 0.849 & 0.397 & \\
\hline complications & 0.078 & 0.996 & 0.321 & \\
\hline
\end{tabular}

\subsection{Prevalence of diabetes-related emotional distress}

Thirteen patients $(8.8 \%)$ experienced diabetes-related distress (PAID $\geq 33$ ). Scores were not significantly different between men and women ( $\mathrm{MD}=-3.17,95 \% \mathrm{CI}$ : -7.86 to 1.52$)$ or between those who were or were not stressed by a life event in the last 12 months $(p=.23)$. The main PAID items scored concerned negative emotions.

\subsection{Risk factors associated with depression}

Hierarchical multiple regression analyses were carried out to investigate the influence of different factors on depression (see Table 3). Demographic variables were entered at step one, explaining $13.5 \%$ of the variance in depression. Psychosocial variables (PAID and stress due to a life event), entered in step two, explained an additional $21 \%$ of variance. After entry of the clinical variables in step three, the total variance explained by the model was $35.4 \%,(\mathrm{~F}(9,135)=8.2, p=$ $<.001$ ). In this model, diabetes-related distress (assessed by PAID scale; beta $=-.39, p<.001$ ), stress due to a life event (beta $=-.28, p<.001$ ), female gender (beta $=-.16, p=-.047$ ), and educational level (beta $=-.16, p=0.054$ ) were significant risk factors for depression.

Table 4. Demographic, psychosocial, and clinical predictors of diabetes-related emotional distress (PAID) in type 2 diabetes patients

\begin{tabular}{|c|c|c|c|c|}
\hline Final model & Standardized Beta & $t$ & $p$ & R square \\
\hline \multicolumn{5}{|c|}{ 1. Demographic variables } \\
\hline female & 0.077 & 0.920 & 0.359 & \\
\hline low education & -0.081 & -1.018 & 0.310 & \\
\hline relation & 0.121 & 1.568 & 0.119 & \\
\hline \multirow[t]{2}{*}{ age } & -0.143 & -1.692 & 0.093 & \\
\hline & & & & 0.060 \\
\hline \multicolumn{5}{|c|}{ 2. Psychosocial variables } \\
\hline WHO-5 scores & -0.438 & -5.306 & 0.000 & \\
\hline \multirow[t]{2}{*}{ life events } & -0.099 & -1.230 & 0.221 & \\
\hline & & & & 0.218 \\
\hline \multicolumn{5}{|l|}{ 3. Clinical variables } \\
\hline duration of diabetes & 0.084 & 1.070 & 0.287 & \\
\hline $\mathrm{HbA1C}$ & 0.234 & 3.111 & 0.002 & \\
\hline \multirow[t]{2}{*}{ complications } & 0.081 & 0.980 & 0.329 & \\
\hline & & & & 0.282 \\
\hline
\end{tabular}




\subsection{Risk factors associated with diabetes-related emotional distress}

On hierarchical regression analysis, demographic variables, psychosocial variables, and clinical variables explained $28.2 \%$ of the variance in diabetes-related emotional distress $(\mathrm{F}(9,135)=5.9, p=<.001)$ (see Table 4). WHO-5 scores (beta $=-.44, p<.001)$ and $\mathrm{HbA1C}$ levels (beta $=.23, p<.005)$ were significant risk factors for diabetes-related emotional distress.

\subsection{Discussion}

In the present study, 33 patients (22.4\%) experienced poor well-being (WHO-5 $\leq 50)$, including 19 patients $(12.9 \%)$ who had depression (WHO-5 $\leq 28$ ). Thirteen patients $(8.8 \%)$ experienced diabetes-related distress (PAID $\geq 33$ ). Corrected for four patients who scored low well-being as well as elevated diabetes-related distress, in total, 28 patients (19.0\%) suffered from depression or distress. Risk factors for depression were elevated diabetes-related distress, measured by the PAID; female gender; stress due to a life event experienced in the last 12 months, and educational level. Risk factors for diabetes-related distress were decreased well-being, measured with the WHO-5 scale, and elevated HbA1C levels.

The prevalence of poor well-being was slightly lower than in other studies ${ }^{[18,19,21,37,38]}$. This might be due to differences in setting, assessment instruments or basic characteristics of the study population such as age, where younger age $(<64)$ was reported as a risk factor for depression in diabetes patients ${ }^{[19]}$. Although the same assessments instruments were used, another Dutch multicenter study reported a higher prevalence of low WHO-5 scores (25\% vs. $12.9 \%)^{[18]}$. This discrepancy could be due to differences in study population such as patients with severe co-morbidity and complications versus relatively healthy subjects ${ }^{[21]}$. While the patients included in the current study were of Caucasian origin, Power et al. attributed the high prevalence of depression in their study to the high proportion (27\%) of participants with a migrant background ${ }^{[18]}$.

The total mean PAID score was lower in the current study than in other studies ${ }^{[23,27,35,39]}$, which might be due to the older age of the study participants and their Caucasian background. PAID items related to negative emotions contributed the most to diabetes-related distress, as has been reported previously ${ }^{[23,35]}$.

Several limitations of this study need to be mentioned. First, $36 \%$ of the patients who gave their informed consent failed to return completed questionnaires. Although the characteristics of the study patients were comparable with those of the diabetes population in the diabetes center under investigation, the authors cannot rule out some selection bias. Second, the cross-sectional study design means that it is not possible to draw long-term conclusions. Third, because the study population consisted exclusively of patients of Caucasian origin, conclusions cannot be drawn about other populations.

Despite these limitations, the results of the present study are potentially of clinical value. The study was performed in a general hospital setting, which may increase the generalizability of the results. Furthermore, according to the informed consent of the participants, the investigator reports all patients who were positively screened for depression or distress to their physicians. Subsequently, the physicians offered a selection of these patients (i.e. who were not receiving psychological care yet), a referral to a psychologist who is also a member of the multi-disciplinary diabetes team.

Another point of clinical value is that structural screening for and monitoring of psychosocial distress of patients with diabetes by DNSs is not common in the Netherlands yet. Anticipating on a Dutch upcoming multi-disciplinary diabetes guideline to support screening for and monitoring of psychological distress, DNSs were involved in this baseline study by inviting the patients and explaining the study. Although their involvement was limited, this seemed to be an essential format in clinical practice for detecting patients with psychosocial burden. These nurses have an intensive, longrelationship with patients and already play a key role in counseling the process of behavioral change and supporting self-management in their patients. The DNSs however, experienced a lack of skills for discussing psychological issues when this occurred. DNSs indicated they need training before structural screening is implemented, in which they can 
probably play a role. According to their opinion, this training should include training of communications skills, knowledge of risk factors, the use of recommended screenings-instruments with corresponding cut-off scores, referral indications and understanding of organizational conditions (e.g. responsibilities, follow-up, reimbursement policies). Also valuable to realize, is that the variance in depression or diabetes-related distress is mainly explained by psychosocial variables rather than demographic and clinical variables. The present study identified in addition to well-known demographic, clinical, and psychosocial factors, 'stress due to life events' in the past 12 months as a significant risk factor of depression, as being very recently published by others ${ }^{[22]}$. Finally, the results of our study shows that a great deal of the variance in psychosocial distress is not explained yet, which represents a challenge for future research.

\section{Conclusion}

Depression was more common in the study population than in the general Dutch population ( $20 \%$ vs. $6 \%$ ). In addition to well-known demographic, clinical, and psychosocial factors, 'stress due to life events' was identified as a significant risk factor of depression.

\section{Practice implications}

Findings provide support for the recommendation to screen patients with type 2 diabetes for depression and diabetesrelated distress, in which DNSs can probably play a role. Paying attention to significant risk factors during regular contacts can be valuable for DNSs in detecting and monitoring psychological distress; which may improve treatment outcomes. New studies are needed to substantiate the impact of our findings and investigate risk factors in clinical practice.

\section{Authors contributions}

A.F researched and analyzed data and wrote the manuscript. A.F. has full access to all collected data in the study. A.F. was responsible for the integrity of the data and the accuracy of the data analysis. B.S contributed to study management and to the discussion and reviewed/ edited the manuscript. H. v. O contributed to the statistical analysis of the data and to the discussion and reviewed/edited the manuscript. A.K contributed to the discussion and reviewed and edited the manuscript.

\section{Acknowledgments}

This research project has been made possible by a contribution of Roche Netherland BV. This organization had no role in any part of the approval, design and conduct of the study or article.

\section{References}

[1] Shaw JE, Sicree RA, Zimmet PZ. Global estimates of the prevalence of diabetes for 2010 and 2030. Diabetes Res Clin Pract. 2010; 87(1): 4-14.

[2] IDF Clinical Guidelines Task Force. Global guideline for type 2 diabetes: Recommendations for standard, comprehensive, and minimal care. Diabet.Med. 2006; 23: 579-593. PMid:16759299 http://dx.doi.org/10.1111/j.1464-5491.2006.01918.x

[3] Barlow J, Wright C, Sheasby J, Turner A, Hainsworth J. Self-management approaches for people with chronic conditions: A review. Patient Educ Couns. 2002 Oct -Nov; 48(2):177-87. http://dx.doi.org/10.1016/S0738-3991(02)00032-0

[4] Pouwer F, Snoek FJ, van der Ploeg HM, Ader HJ, Heine RJ. Monitoring of psychological well-being in outpatients with diabetes: Effects on mood, $\mathrm{HbA}(1 \mathrm{c})$, and the patient's evaluation of the quality of diabetes care: A randomized controlled trial. Diabetes Care. 2001 Nov; 24(11): 1929-35. PMid:11679459 http://dx.doi.org/10.2337/diacare.24.11.1929

[5] Vrijhoef HJ, Diederiks JP, Spreeuwenberg C, Wolffenbuttel BH, van Wilderen LJ. The nurse specialist as main care-provider for patients with type 2 diabetes in a primary care setting: Effects on patient outcomes. Int J Nurs Stud. 2002 May; $39(4)$ : $441-51$. http://dx.doi.org/10.1016/S0020-7489(01)00046-3

[6] Sol BG, van der Bijl JJ, Banga JD, Visseren FL. Vascular risk management through nurse-led self-management programs. J Vasc Nurs. 2005 Mar; 23(1): 20-4. PMid:15741961 http://dx.doi.org/10.1016/j.jvn.2004.12.003 
[7] Rubin RR, Peyrot M. Psychological issues and treatments for people with diabetes. J Clin Psychol. 2001 Apr; 57(4): 457-78. PMid:11255202 http://dx.doi.org/10.1002/jclp.1041

[8] Schoemaker C, Poos M, Spijker J, Gool C. Hoe vaak komt depressie voor? In: Volksgezondheid toekomst verkenning, nationaal kompas volksgezondheid. 2010.

[9] Ali S, Stone MA, Peters JL, Davies MJ, Khunti K. The prevalence of co-morbid depression in adults with type 2 diabetes: A systematic review and meta-analysis. Diabet Med. 2006 Nov; 23(11): 1165-73. PMid:17054590 http://dx.doi.org/10.1111/j.1464-5491.2006.01943.x

[10] Ciechanowski PS, Katon WJ, Russo JE, Hirsch IB. The relationship of depressive symptoms to symptom reporting, self-care and glucose control in diabetes. Gen Hosp Psychiatry. 2003 Jul-Aug; 25(4): 246-52. http://dx.doi.org/10.1016/S0163-8343(03)00055-0

[11] Lustman PJ, Anderson RJ, Freedland KE, de Groot M, Carney RM, Clouse RE. Depression and poor glycemic control: A meta-analytic review of the literature. Diabetes Care. 2000 Jul; 23(7): 934-42. PMid:10895843 http://dx.doi.org/10.2337/diacare.23.7.934

[12] Lustman PJ, Clouse RE. Depression in diabetic patients: The relationship between mood and glycemic control. J Diabetes Complications. 2005 Mar-Apr; 19(2):113-22. http://dx.doi.org/10.1016/S1056-8727(04)00004-2

[13] Black SA, Markides KS, Ray LA. Depression predicts increased incidence of adverse health outcomes in older mexican americans with type 2 diabetes. Diabetes Care. 2003 Oct; 26(10):2822-8. PMid:14514586 http://dx.doi.org/10.2337/diacare.26.10.2822

[14] Gonzalez JS, Vileikyte L, Ulbrecht JS, Rubin RR, Garrow AP, Delgado C, et al. Depression predicts first but not recurrent diabetic foot ulcers. Diabetologia. 2010 Oct; 53(10):2241-8. PMid:20556354 http://dx.doi.org/10.1007/s00125-010-1821-x

[15] Akhtar S, Schaper N, Apelqvist J, Jude E. A review of the eurodiale studies: What lessons for diabetic foot care? Curr Diab Rep. 2011 Aug;11(4):302-9. PMid:21573866 http://dx.doi.org/10.1007/s11892-011-0195-x

[16] Katon W, von Korff M, Ciechanowski P, Russo J, Lin E, Simon G, et al. Behavioral and clinical factors associated with depression among individuals with diabetes. Diabetes Care. 2004 Apr; 27(4):914-20. PMid:15047648 http://dx.doi.org/10.2337/diacare.27.4.914

[17] Schram MT, Baan CA, Pouwer F. Depression and quality of life in patients with diabetes: A systematic review from the european depression in diabetes (EDID) research consortium. Curr Diabetes Rev. 2009 May; 5(2):112-9. PMid:19442096 http://dx.doi.org/10.2174/157339909788166828

[18] Pouwer F, Geelhoed-Duijvestijn PH, Tack CJ, Bazelmans E, Beekman AJ, Heine RJ, et al. Prevalence of comorbid depression is high in out-patients with type 1 or type 2 diabetes mellitus. Results from three out-patient clinics in the netherlands. Diabet Med. 2010 Feb; 27(2):217-24. PMid:20546267 http://dx.doi.org/10.1111/j.1464-5491.2009.02903.x

[19] Egede LE, Zheng D. Independent factors associated with major depressive disorder in a national sample of individuals with diabetes. Diabetes Care. 2003 Jan; 26(1): 104-11. PMid:12502665 http://dx.doi.org/10.2337/diacare.26.1.104

[20] Leach LS. Review: Major depression affects about 7\% of adults aged 75 and above. Evid Based Ment Health. 2012 Aug; $15(3): 64$. PMid:22611071 http://dx.doi.org/10.1136/ebmental-2012-100694

[21] Pouwer F, Beekman AT, Nijpels G, Dekker JM, Snoek FJ, Kostense PJ, et al. Rates and risks for co-morbid depression in patients with type 2 diabetes mellitus: Results from a community-based study. Diabetologia. 2003 Jul; 46(7): 892-8. PMid:12819896 http://dx.doi.org/10.1007/s00125-003-1124-6

[22] Snoek FJ, Kersch NY, Eldrup E, Harman-Boehm I, Hermanns N, Kokoszka A, et al. Monitoring of individual needs in diabetes (MIND)-2: Follow-up data from the cross-national diabetes attitudes, wishes, and needs (DAWN) MIND study. Diabetes Care. 2012 Jul 26. PMid:22837364 http://dx.doi.org/10.2337/dc11-1326

[23] Delahanty LM, Grant RW, Wittenberg E, Bosch JL, Wexler DJ, Cagliero E, et al. Association of diabetes-related emotional distress with diabetes treatment in primary care patients with type 2 diabetes. Diabet Med. 2007 Jan; 24(1): 48-54. PMid:17227324 http://dx.doi.org/10.1111/j.1464-5491.2007.02028.x

[24] Pouwer F, Beekman AT, Lubach C, Snoek FJ. Nurses' recognition and registration of depression, anxiety and diabetes-specific emotional problems in outpatients with diabetes mellitus. Patient Educ Couns. 2006 Feb; 60(2): 235-40. PMid:16442465 http://dx.doi.org/10.1016/j.pec.2005.01.009

[25] American Diabetes Association. Standards of medical care in diabetes--2006. Diabetes Care. 2006 Jan; 29 Suppl 1: S4-42. PMid:16373931

[26] Fisher L, Skaff MM, Mullan JT, Arean P, Glasgow R, Masharani U. A longitudinal study of affective and anxiety disorders, depressive affect and diabetes distress in adults with type 2 diabetes. Diabet Med. 2008 Sep; 25(9): 1096-101. PMid:19183314 http://dx.doi.org/10.1111/j.1464-5491.2008.02533.x

[27] Hermanns N, Kulzer B, Krichbaum M, Kubiak T, Haak T. How to screen for depression and emotional problems in patients with diabetes: Comparison of screening characteristics of depression questionnaires, measurement of diabetes-specific emotional 
problems and standard clinical assessment. Diabetologia. 2006 Mar; 49(3): 469-77. PMid:16432706

http://dx.doi.org/10.1007/s00125-005-0094-2

[28] World Medical Association General Assembly. World medical association declaration of helsinki: Ethical principles for medical research involving human subjects (revised october 7, 2000). HIV Clin Trials. 2001 Jan-Feb; 2(1): 92-5. PMid:11590516 http://dx.doi.org/10.1310/GTFR-2DRX-M6YE-ELXR

[29] Bech P, Gudex C, Johansen KS. The WHO (ten) well-being index: Validation in diabetes. Psychother Psychosom. 1996; 65(4): 183-90. PMid:8843498 http://dx.doi.org/10.1159/000289073

[30] Bech P, Olsen LR, Kjoller M, Rasmussen NK. Measuring well-being rather than the absence of distress symptoms: A comparison of the SF-36 mental health subscale and the WHO-five well-being scale. Int J Methods Psychiatr Res. 2003; 12(2): 85-91. PMid:12830302 http://dx.doi.org/10.1002/mpr.145

[31] Lowe B, Spitzer RL, Grafe K, Kroenke K, Quenter A, Zipfel S, et al. Comparative validity of three screening questionnaires for DSM-IV depressive disorders and physicians' diagnoses. Journal of Affective Disorders. 2004; 78(2): 131-140. http://dx.doi.org/10.1016/S0165-0327(02)00237-9

[32] Awata S, Bech P, Yoshida S, Hirai M, Suzuki S, Yamashita M, et al. Reliability and validity of the japanese version of the world health organization-five well-being index in the context of detecting depression in diabetic patients. Psychiatry Clin Neurosci. 2007 Feb; 61(1): 112-9. PMid:17239048 http://dx.doi.org/10.1111/j.1440-1819.2007.01619.x

[33] American Psychatric Association. Diagnostic and statistical manual of mental disorders DSM-IV-TR fourth edition. text revision edition. 2000.

[34] Polit D.F. BCT,. Internal consistency. In: Nursing Research: Generating and Assessing Evidence for Nursing Practice. 8th ed. Philadelphia: Lippinncott, Williams and Wilkins; 2008. p. 454-5.

[35] Snoek FJ, Pouwer F, Welch GW, Polonsky WH. Diabetes-related emotional distress in dutch and U.S. diabetic patients: Cross-cultural validity of the problem areas in diabetes scale. Diabetes Care. 2000 Sep; 23(9): 1305-9. PMid:10977023 http://dx.doi.org/10.2337/diacare.23.9.1305

[36] Polit D.F. BCT,. Sample size for multiple regression. In: Nursing Research: Generating and Assessing Evidence for Nursing Practice. 8th ed. Philadelphia: Lippincott Williams and Wilkins; 2008. p. 623.

[37] Anderson RJ, Freedland KE, Clouse RE, Lustman PJ. The prevalence of comorbid depression in adults with diabetes: A meta-analysis. Diabetes Care. 2001 Jun; 24(6):1069-78. PMid:11375373 http://dx.doi.org/10.2337/diacare.24.6.1069

[38] Nichols GA, Brown JB. Unadjusted and adjusted prevalence of diagnosed depression in type 2 diabetes. Diabetes Care. 2003 Mar; 26(3): 744-9. PMid:12610032 http://dx.doi.org/10.2337/diacare.26.3.744

[39] Snoek FJ, Kersch NY, Eldrup E, Harman-Boehm I, Hermanns N, Kokoszka A, et al. Monitoring of individual needs in diabetes (MIND): Baseline data from the cross-national diabetes attitudes, wishes, and needs (DAWN) MIND study. Diabetes Care. 2011 Mar; 34(3): 601-3. PMid:21266654 http://dx.doi.org/10.2337/dc10-1552 